\title{
AN ENERGETIC TYPE MODEL FOR THE CROSS-SHORE DISTRIBUTION OF TOTAL LONGSHORE SEDIMENT TRANSPORT
}

\author{
Cüneyt Baykal ${ }^{1}$, Ayșen Ergin² and Ișıkhan Güler ${ }^{3}$
}

\begin{abstract}
This paper presents an energetic-based simple approach for the computation of cross-shore distribution of total longshore sediment transport (LST) rates. The proposed approach (Baykal 2012) follows similar assumptions with the given formula of Bayram et al. (2007) for the total LST rate $\left(\mathrm{Q}_{\mathrm{lst}, t}\right)$ across the surf zone and is applied to investigate the relation between the rate of dissipation in wave energy flux due to wave breaking and total longshore sediment flux using the available laboratory measurements of Wang et al. (2002) and Gravens and Wang (2007) and the field measurements carried out at Duck site, North Carolina, USA between years 1995-1998 (Miller 1999). The proposed approach is also compared with some of the available distributed total load models. From the comparative studies, it is found that the proposed approach shows good agreement with both the laboratory and field measurements, using a single empirical constant, both qualitatively and quantitatively, especially for the cases where the wave conditions are highly energetic (both for plunging and spilling type breakers) and the suspended load is the main mode of sediment transport in the surf zone.
\end{abstract}

Keywords: longshore sediment transport; cross-shore distribution; wave breaking

\section{INTRODUCTION}

Over the years, numerous approaches have been developed for the prediction of longshore sediment transport (LST) rates within the surf zone due to waves and currents. Inman-Bagnold (1963), CERC (USACE, 1984) and Kamphuis (1991) formulas are the most well-known and utilized formulas for the prediction of total LST rates within the surf zone due to breaking waves for the problems where the knowledge of cross-shore distribution of LST is not the primary concern (i.e. oneline models). Meanwhile, advances in computer technology and numerical modeling encouraged the development and use of more sophisticated formulas and approaches for the computation of spatial distribution of sediment transport rates in nearshore environments and different modes of transport such as bed or suspended loads to be used mostly in complex numerical models for sediment transport and bottom evolution problems. Bagnold (1963), Bijker (1967, 1971), Engelund and Hansen (1967), Ackers and White (1973), Bodge (1989), Van Rijn (1984), Watanabe (1992) and more recently Camenen and Larson (2005, 2007 and 2008), Kobayashi et al. (2007) and Kuriyama (2010) are some of these distributed sediment transport rate formulas. These approaches are mainly divided into two categories; the "energetics" models, which assume the mobilizing mechanism is a function of wave energy dissipation, and "stress" models, in which shear stress exerted on the bottom by waves and currents mobilize sediment. Bodge and Dean (1987), Bayram et al. (2001) and Van Maanen et al. (2009) give evaluation of the various distributed sediment transport approaches and compare their capabilities in predicting the cross-shore distribution of LST rates for the selected data sets.

Accurate prediction of non-cohesive sediment transport rates in nearshore environments requires an extensive amount of work due to numerous variables and physical processes involved, complexity and randomness of the processes and interactions between these processes. Consequently, the sediment transport formulas that are simple, robust and accurate enough for a wide range of conditions have usually been more preferable for engineering purposes and numerical modeling studies. In this study, the main objective is to investigate the relation between the energy dissipation rates due to random wave breaking and the distributed total LST rates using the existing knowledge in the literature and to develop an alternative and simple approach for the computation of cross-shore distribution of the total LST rate to be implemented in the beach evolution models. Based on the assumption that the local total sediment transport rates across the surf zone are proportional to the rate of dissipation of wave energies due to wave breaking and wave-induced current velocities, such an approach is proposed in this study and the validity of the proposed approach is investigated with the available laboratory and field measurements.

\footnotetext{
${ }^{1}$ Dr., Dept. of Civil Eng., Middle East Technical University, Dumlupınar Blv., Çankaya, Ankara, 06800, Turkey

2 Prof.Dr., Dept. of Civil Eng., Middle East Technical University, Dumlupınar Blv., Çankaya, Ankara, 06800, Turkey

${ }^{3}$ Dr., Yüksel Proje Uluslararası A.Ş., Birlik Mah. 450 Cad. No:23, Çankaya, Ankara, 06610, Turkey
} 


\section{METHODOLOGY}

The main assumption of the proposed approach is that the distributed total sediment transport rates across the surf zone are proportional to the rate of dissipation of wave energies due to wave breaking and wave-induced current velocities.

The proposed approach follows similar assumptions as given in Bayram et al. (2007). Suspended sediment transport is assumed to be the governing mode of transport in the surf zone where the strong the wave action mobilize the sediment and keep in suspension so that transported by the currents. The sediment transport outside the surf zone is assumed to be insignificant compared to the surf zone. The total amount of work $\left(W=\varepsilon \cdot F_{b}\right)$ needed to keep the sediment in suspension is related to a certain portion $(\varepsilon)$ of the energy flux of the breaking waves $\left(F_{b}\right)$;

$$
F_{b}=E_{b} C_{g b} \cos \theta_{b}
$$

where $C_{g b}$ is the group velocity of the breaking waves, $E_{b}$ is the total breaking wave energy, and the $\theta_{b}$ is the approach angle of the breaking waves.

Similary, in the proposed approach, the total work $\left(w^{*}\right)$ needed to keep sediments in suspension per unit length in cross-shore direction is done by a certain part $(\varepsilon)$ of the rate of dissipation in wave energy flux due to wave breaking $\left(w^{*}=\varepsilon \cdot D_{b}\right)$, and the steady state conditions prevail for the respective unit length and the sediment concentration in the water column is carried with a depth-averaged longshore current velocity $(v)$.

The total amount of work $\left(w^{*}\right)$ needed to keep the sediment in suspension per unit length $(\Delta x)$ in cross-shore direction is defined as given by the Bayram et al. (2007) as the product of the concentration $(c)$ of the submerged weight of the particle with the fall speed $\left(w_{s}\right)$,

$$
w^{*}=\int_{x}^{x+\Delta x} \int_{-d(x)}^{0} c(x, z) \cdot\left(\rho_{s}-\rho\right) \cdot g \cdot w_{s} \cdot d z \cdot d x
$$

where $x$ is the cross-shore coordinate originating at the shoreline and taken positive offshore, $z$ is the vertical coordinate originating at the still-water level, $d(x)$ is the water depth including mean water level change at $x$. The fall speed of the sediment grains is computed using Ahrens (2000).

The total LST rate per unit length in cross-shore direction can be expressed as the product of concentration $(c)$ and longshore current velocity $(v)$ :

$$
q_{l s t, t}=\int_{x}^{x+\delta x} \int_{-d(x)}^{0} c(x, z) \cdot v(x, z) \cdot d z \cdot d x
$$

Using a depth averaged longshore velocity $(v)$ varying in cross-shore direction only and replacing the integral in Eq.3 with a certain fraction $(\varepsilon)$ of rate of dissipation in wave energy flux due to wave breaking $\left(D_{b}\right)$ similarly varying in cross-shore direction as the depth changes and irregular wave breaking occurs, the following expression is obtained,

$$
q_{l s t, t, S E D}=\frac{\varepsilon \cdot D_{b} \cdot v}{\left(\rho_{s}-\rho\right) \cdot(1-p) \cdot w_{s} \cdot g}
$$

where $q_{l s t, t}$ is the distributed total LST rate in bulk volume per time per unit length in cross-shore direction and $p$ is the in-place sediment porosity. The $\varepsilon$ parameter is taken as 0.002 in regard to the comparative studies with the available data sets of the measured transport rates. Bayram et al. (2007) defines the $\varepsilon$ parameter (hereafter $\varepsilon_{B a 07}$ ) for their total LST formulae through dimensional analysis based on an extensive data set of laboratory and field experiments as

$$
\varepsilon_{B a 07}=\left(4+9 \frac{H_{s, b}}{T_{p} w_{s}}\right) \cdot 10^{-5}
$$

where $H_{s, b}$ is the significant breaking wave height, $T_{p}$ is the peak wave period. The above given approach is applied to several datasets and compared with the other formulations of distributed total LST rate such as two energetic type of approaches Bagnold (1963) and Bodge (1989) and one stress approach, Watanabe (1992). The proposed approach where the $\varepsilon$ parameter is taken as constant $(\varepsilon=0.002)$ is denoted as 'SED1' approach and for $\varepsilon=\varepsilon_{B a 07}$ it is denoted as 'SED2' approach. Both the 
Bagnold (1989) and Bodge (1963) approaches are the energetic type expressions that utilize maximum bottom orbital velocity $\left(u_{0}\right)$ with an empirical constant $(k)$.

$$
q_{l s t, t, B a 63}=\frac{k \cdot D_{b} \cdot v}{\left(\rho_{s}-\rho\right) \cdot(1-p) \cdot u_{0} \cdot g}
$$

Bodge's (1989) expression takes also the water depth $(h)$ into account in the expression.

$$
q_{l s t, t, B o 89}=\frac{k \cdot D_{b} \cdot v}{\left(\rho_{s}-\rho\right) \cdot(1-p) \cdot h \cdot u_{O} \cdot g}
$$

In the comparisons, the $k$ coefficient given for both expressions is selected as to fit the respective dataset best, for laboratory or field experiments. Watanabe's (1992) approach is based on the shear stress concept (or power model concept) that the total load in the longshore direction (in bulk volume including pores) is proportional to the residual between the mean bed shear stress under wave-current field $\left(\tau_{b, c w}\right)$ over a wave-cycle and the critical bed shear stress $\left(\tau_{c r}\right)$ that is required to mobilize the sediment grains at the sea bed,

$$
q_{l s t, t, W 92}=\frac{A \cdot\left[\tau_{b, c w}-\tau_{c r} \mid \cdot v\right.}{\rho \cdot g}
$$

where the $A$ coefficient is given as 0.5 for monochromatic waves and 2.0 for random waves. In the comparisons, it is taken as 1.0 for the laboratory measurements and the 2.0 for the field measurements.

In the comparative studies, the rate of change in the dissipated wave energy flux due to random wave breaking $\left(D_{b}\right)$ while the waves approach to the shoreline is found using the methodology given by Janssen and Battjes (2007). Janssen and Battjes (2007) revisits the derivation of the parametric irregular wave breaking model proposed by Baldock et al. (1998) and proposes a modification resulting in enhanced dissipation rates in steep beaches. The rate of change due to random wave breaking $\left(D_{b}\right)$ in the wave energy flux is given with the below given expression,

$$
D_{b}=\frac{3 \sqrt{\pi}}{16} B f \rho g \frac{H_{r m s}^{3}}{h}\left[1+\frac{4}{3 \sqrt{\pi}}\left(R^{3}+\frac{3}{2} R\right) \exp \left(-R^{2}\right)-\operatorname{erf}(R)\right]
$$

where $B$ is a control parameter for the intensity of dissipation and is taken as $1.0, f$ is the representative frequency of the incoming waves, $g$ is gravitational acceleration, $\rho$ represents the fluid density, $h$ is water depth, and $R$ is the ratio of breaking wave height $\left(H_{b}=\gamma_{b} / H_{r m s}\right)$ to the root mean square wave height $\left(H_{r m s}\right)$ where the breaking index $\left(\gamma_{b}\right)$ is selected as to give the best fitting curve of computed nearshore wave heights for the selected test.

\section{Comparisons with LSTF Movable Bed Experiments (Wang et al. 2002; Gravens and Wang 2007)}

Wang et al. (2002) and Gravens and Wang (2007) conducted series of physical model experiments at the at the Large-scale Sediment Transport Facility (hereafter LSTF) at U.S. Army Engineers Waterways Experiment Station's Coastal Engineering Research Center (CERC) to generate data sets for testing and validation of sediment transport formulas in the presence of waves and currents. The experiments were carried on movable bed with well-sorted quartz sand having a median grain size $\left(d_{50}\right)$ of $0.15 \mathrm{~mm}$ for various flow and wave conditions. The sediment density is given as $2650 \mathrm{~kg} / \mathrm{m}^{3}$, the sea water density is taken as $1000 \mathrm{~kg} / \mathrm{m}^{3}$ and the porosity is given as 0.4 . In this study, measurements of nearshore wave heights, longshore current velocities and the total LST rates of the Test1-Case1, Test3-Case1, Test5-Case1 and Test6 from Wang et al. (2002) and Test-BC1 from Graven and Wang (2007) are used. In selected experiments, no external longshore current is applied to wave conditions and only the wave-induced longshore currents are generated and measured. The experiment conditions, the water depths and the incident wave conditions in front of the wave pistons are summarized in Table 1. 


\begin{tabular}{|c|c|c|c|c|}
\hline Test No & $\begin{array}{l}\text { Offshore Water } \\
\text { Depth, } h(\mathrm{~m})\end{array}$ & $\begin{array}{l}\text { Offshore Sig. } \\
\text { Wave Height, } H_{s} \\
\text { (m) }\end{array}$ & $\begin{array}{l}\text { Peak Wave Period, } \\
T_{p}(\mathrm{sec})\end{array}$ & Breaker Type \\
\hline T1-C1 & 0.9 & 0.25 & 1.5 & Spilling \\
\hline T3-C1 & 0.9 & 0.27 & 3.0 & Plunging \\
\hline T5-C1 & 0.9 & 0.16 & 1.5 & Spilling \\
\hline T6 & 0.9 & 0.19 & 3.0 & Plunging \\
\hline TEST-BC 1 & 0.67 & 0.225 & 1.459 & Spilling \\
\hline
\end{tabular}

As it can be seen from Table 1, the incident wave conditions are composed of steep waves with the breaker types of plunging or spilling. In the computation of the distributed sediment fluxes, the measured longshore velocities are interpolated for the respective measurement points of the sediment fluxes. For the available datasets, the A constant in the Watanabe's (1992) formulation is taken as 1.0 as suggested for the laboratory experiments, the empirical coefficient $k$ for the Bagnold (1963) and Bodge (1989) expressions is taken 1/36 and 1/22 respectively. The comparisons of the measured and computed significant wave heights and the distributed total LST rates for the experiments T1-C1 and T6 are given in Figure 1 and Figure 2 respectively.
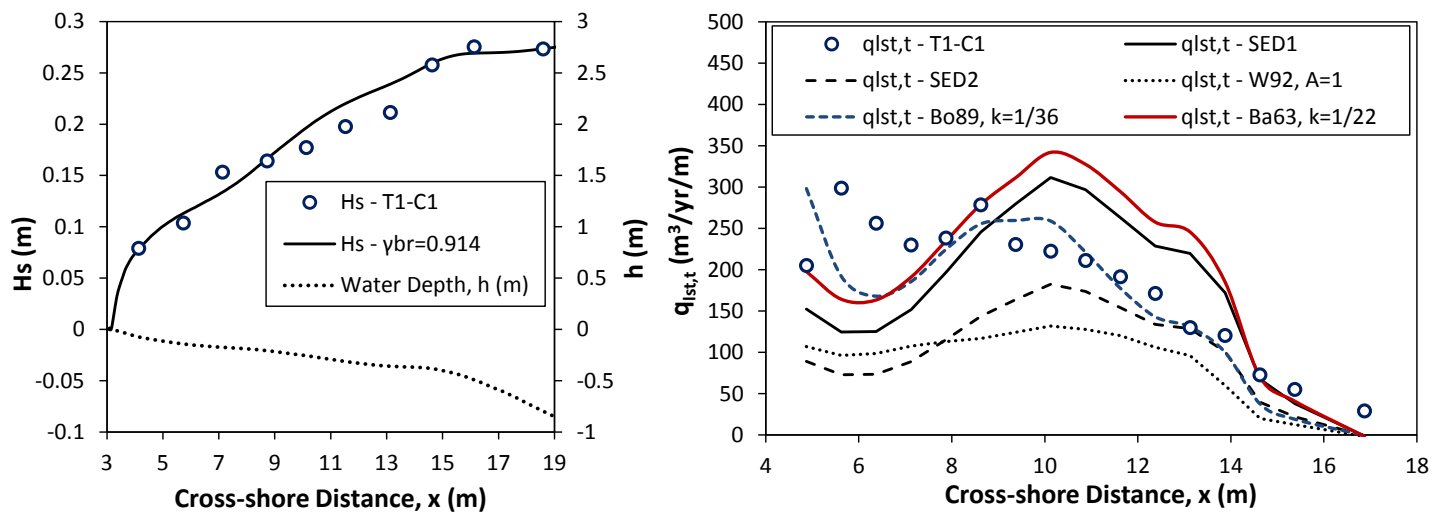

Figure 1. The measured and computed significant wave heights (left) and distributed total LST rates (right) for T1-C1 (Wang et al., 2002).
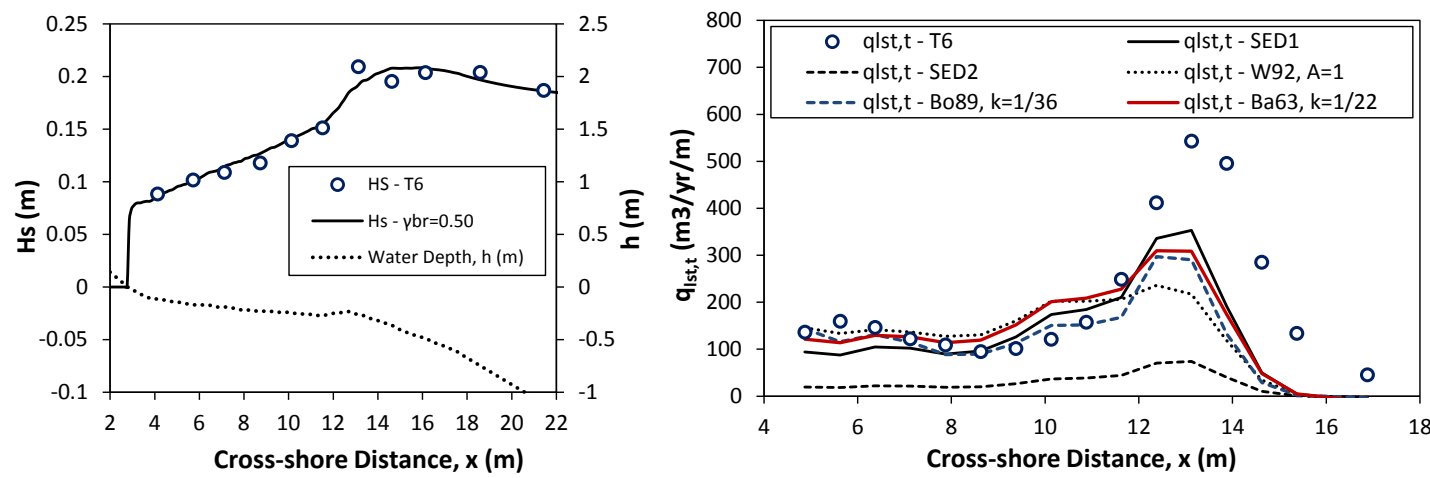

Figure 2. The measured and computed significant wave heights (left) and distributed total LST rates (right) for T6 (Wang et al., 2002).

As it can be seen from Figure 1 and 2, the computed nearshore significant wave heights are in good agreement with the measurements. In Figure 1 (right), Bodge's (1989) expression provides a better estimate for the change in the sediment flux along the cross-shore profile compared the others. 
In Figure 2 (right), Bagnold (1963) and the SED1 expressions provide better estimates for the change in the sediment flux along the cross-shore profile compared to the others.

\section{Comparisons with SANDYDUCK Measurements (Miller 1999)}

The SANDYDUCK experiments were conducted at the Field Research Facility (FRF) Pier of the CERC, at the Duck site, North Carolina, USA (Miller, 1999) to investigate nearshore sediment transport processes during moderate storm conditions (individual wave heights up to $5 \mathrm{~m}$ and spilling breakers). The sediment grain size distribution for the site is given as bimodal with a main component around $0.25 \mathrm{~mm}$ and a secondary component near $1.0 \mathrm{~mm}$. In the bar-trough region, sediment grain size distribution is given as uni-modal with a median grain size of $0.17 \mathrm{~mm}$. At the seaward of the bar-trough region, the sediments are well sorted with a median diameter of $0.12 \mathrm{~mm}$ (Miller, 1999). In the comparisons, it is assumed that the median grain size diameter is $0.17 \mathrm{~mm}$. The sediment density is given as $2650 \mathrm{~kg} / \mathrm{m}^{3}$, the sea water density is given as $1025 \mathrm{~kg} / \mathrm{m}^{3}$ and the porosity is given as 0.4. During the experiments, the bed load and sediment load in the swash zone are not measured, yet, it is likely that the measured transport rates in the sampled zone include most of the transport. Bayram et al. (2001) state that the sediment transport for all SANDYDUCK experiments is in the sheet flow regime (highly concentrated suspended sediment transport) in the surf zone, which occurs under storm conditions.

During the experiments, the wave heights, longshore and cross-shore current velocities and time averaged suspended sediment concentrations at various depths along the cross-shore profile $15 \mathrm{~m}$ away from the pier pilings and up to $9 \mathrm{~m}$ water depth were measured by a vertical array of instruments attached to the lower boom of a track-mounted crane. The details of the measurements are given in Miller (1999).

During the experiments, the offshore wave conditions were measured from a (directional) pressure gauge array located at a depth of $8 \mathrm{~m}$ ( $8 \mathrm{~m}$ Array; slightly offshore and north of the FRF pier) and a directional waverider $3 \mathrm{~km}$ offshore at $17.4 \mathrm{~m}$ water depth. The offshore wave conditions based on $8 \mathrm{~m}$ array measurements are given in Table 2 (Miller, 1999).

\begin{tabular}{|c|c|c|c|c|}
\hline Date & $\begin{array}{l}\text { Mean Bottom } \\
\text { Slope, } 1 / \mathrm{m}\end{array}$ & $\begin{array}{l}\text { Offshore Sig. Wave } \\
\text { Height, } H_{s}(\mathrm{~m})\end{array}$ & $\begin{array}{l}\text { Peak Wave Period, } T_{p} \\
(\mathrm{sec})\end{array}$ & $\begin{array}{l}\text { Offshore Mean } \\
\text { Approach Angle, } \bar{\theta} \\
\text { (deg) }\end{array}$ \\
\hline March 11, 1996 & $1: 74.8$ & 2.8 & 7 & 10 \\
\hline March 27, 1996 & $1: 71.6$ & 1.8 & 6.7 & 25 \\
\hline April 2, 1996 & $1: 85.3$ & 1.6 & 7 & 26 \\
\hline March $31,1997^{*}$ & $1: 69.7$ & 1.5 & 7 & 39 \\
\hline April 1, 1997 & $1: 71.6$ & 2.7 & 9 & 18 \\
\hline October 19, 1997 & $1: 73$ & 3 & 10 & 20 \\
\hline October $20,1997^{*}$ & $1: 76.8$ & 2.2 & 11 & 7 \\
\hline February 4, 1998 & $1: 60.1$ & 3.8 & 11 & 20 \\
\hline February 5, 1998* & $1: 77.2$ & 3.1 & 12 & 8 \\
\hline
\end{tabular}

As it can be seen from Table 2, the measured significant wave heights are in in the range of 1.5$3.8 \mathrm{~m}$ with the peak periods ranging from 6.7 to $12 \mathrm{~s}$ for the available experiments. The comparisons of the measured and computed significant wave heights and the distributed LST rates for the experiments February $4^{\text {th }}$ and October $19^{\text {th }} 1998$ are given in Figure 3 and Figure 4 respectively. 

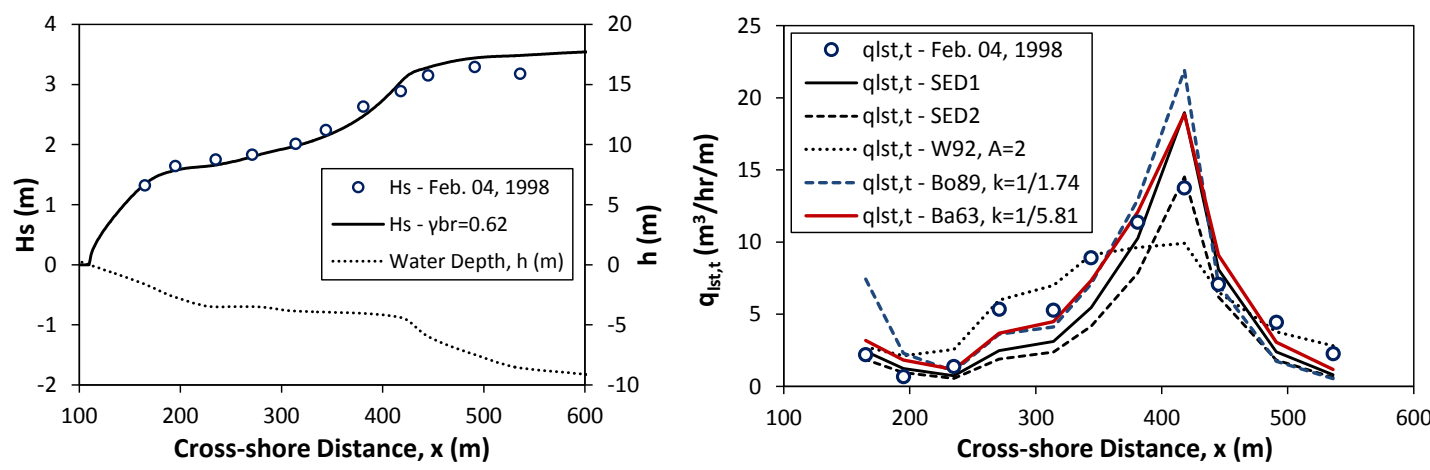

Figure 3. The measured and computed significant wave heights (left) and distributed total LST rates (right) for Sandyduck 04 February 1998 experiment (Miller 1999).
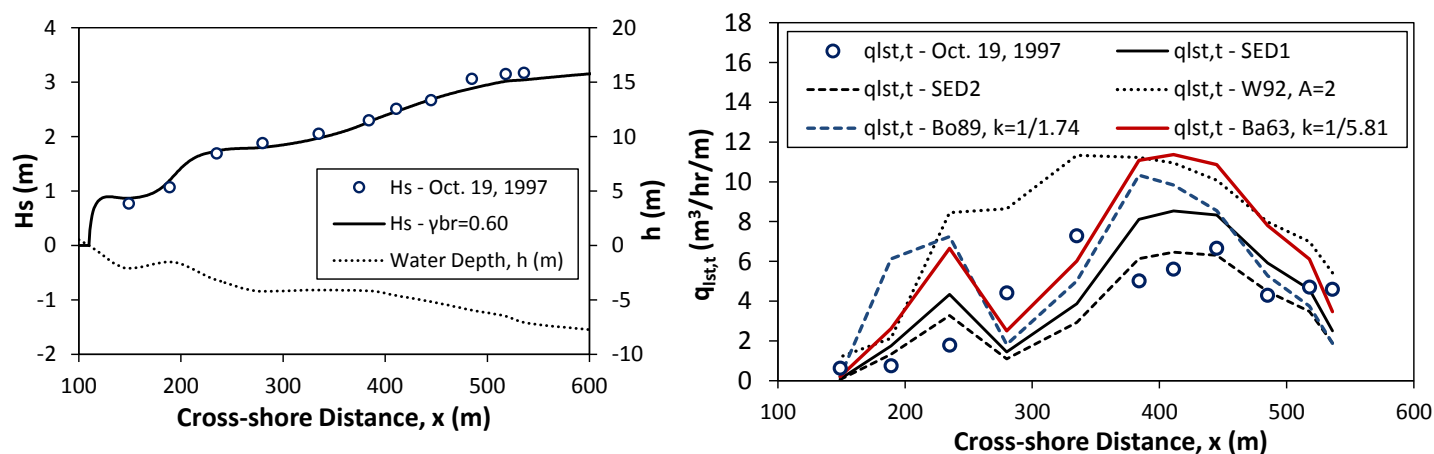

Figure 4. The measured and computed significant wave heights (left) and distributed total LST rates (right) for Sandyduck 19 October 1998 experiment (Miller 1999).

As it can be seen from Figure 3 and 4, the computed nearshore significant wave heights are in good agreement with the measurements. In Figure 3 (right), Bagnold (1963) and the SED1 expressions provide better estimate for the change in the sediment flux along the cross-shore profile compared the others. In Figure 4 (right), the SED1 expression provide a better estimate for the change in the sediment flux along the cross-shore profile compared to the others.

\section{DISCUSSION OF RESULTS}

Quantitative and qualitative comparisons are made through computing the mean absolute percent error $\left(E_{\text {mean }}\right)$, scatter $\left(\sigma_{r m s}\right)$ and the percent discrepancy ratios which gives the percentage of the number of data points outlying the limits of 0.5-2.0, 0.25-4.0 and 0.2-5.0 of the measured flux values. The mean absolute error and the scatterness (Bayram et al. 2007) are computed with the below given equations respectively where $\mathrm{N}$ is the number of data used.

$$
\begin{gathered}
E_{\text {mean }}=100 \cdot \overline{\left[\frac{\left|q_{l s t, t, \text { measured }}-q_{l s t, t, \text { predicted }}\right|}{q_{l s t, t, \text { measured }}}\right]} \\
\sigma_{r m s}=\left[\frac{\sum\left[\log \left(q_{l s t, t, \text { measured }}\right)-\log \left(q_{l s t, t, \text { predicted }}\right)\right]^{2}}{N-1}\right]^{1 / 2}
\end{gathered}
$$

The measured laboratory and field transport rates and predicted transport rates using SED1 approach are plotted in Figure 5. The mean absolute percent errors, the scatternesses and the discrepancy ratios of the predicted transport rates for different formulations are given in Table 3 and Table 4 for the laboratory and field experiments respectively. 


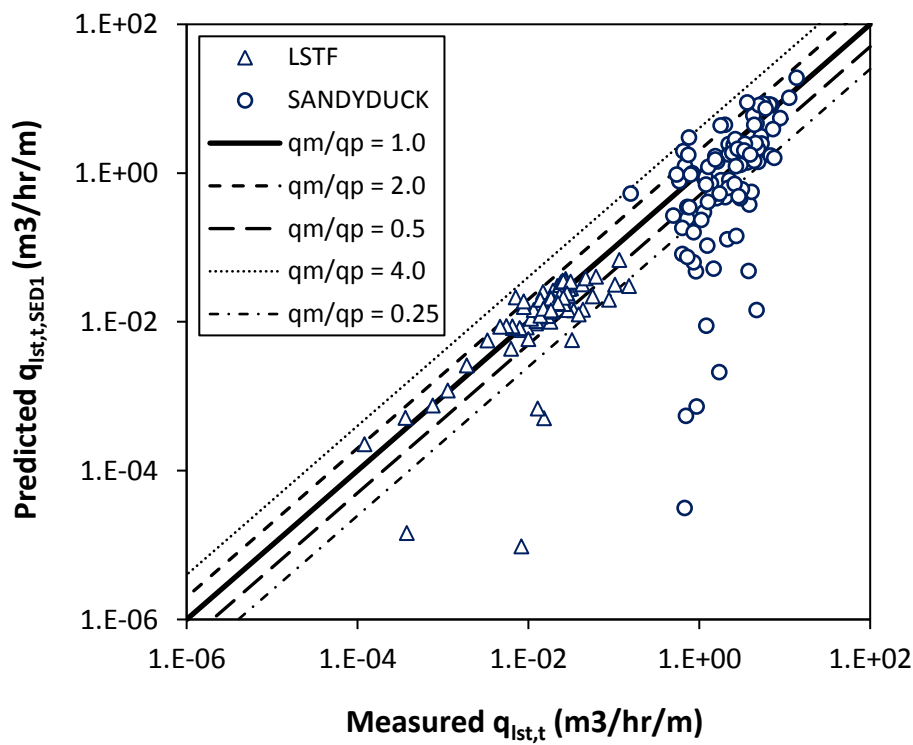

Figure 5. Measured vs. predicted (SED1) total LST rates for the laboratory (triangles) and field experiments (circles)

As it is seen from Figure 5, the SED1 approach, which uses the same empirical constant $(\varepsilon=0.002)$ for both the laboratory and field experiments, shows a good agreement with the datasets available. More than $80 \%$ of the predicted transport rates lie within a factor of range $0.25-4.0$ of the measured values.

Table 3. Summary of accuracy of the formulas for the LSTF Movable Bed Experiments (Gravens and Wang 2007; Wang et al. 2002)

\begin{tabular}{|l|l|l|l|l|}
\hline \multirow{2}{*}{ Formulas } & Mean Absolute Percent Error, & Scatter, $\boldsymbol{\sigma}_{\text {rms }}$ & \multicolumn{2}{l|}{ Discrepancy Ratio (\%) } \\
\cline { 4 - 5 } & $\mathrm{E}_{\text {mean }}(\%)$ & $\mathbf{1 / 2} \mathbf{- 2 . 0}$ & $\mathbf{1 / 4} \mathbf{- 4 . 0}$ \\
\hline SED1 $(\varepsilon=0.002)$ & 39.5 & 0.49 & 19.2 & 9.0 \\
\hline SED2 $\left(\varepsilon=\varepsilon_{\text {Ba07 }}\right)$ & 62.6 & 0.77 & 75.6 & 32.1 \\
\hline Watanabe $(1992)(A=1.0)$ & 56.0 & 0.47 & 35.9 & 12.8 \\
\hline Bodge $(1989)-\mathrm{k}=1 / 36$ & 33.0 & 0.58 & 56 & 33.3 \\
\hline Bagnold $(1963)-\mathrm{k}=1 / 22$ & 47.0 & 0.47 & 62 & 23.9 \\
\hline
\end{tabular}

Table 4. Summary of accuracy of the formulas for the LSTF Movable Bed Experiments (Gravens and Wang 2007; Wang et al. 2002)

\begin{tabular}{|l|l|l|l|l|}
\hline \multirow{2}{*}{ Formulas } & Mean Absolute Percent Error, & Scatter, $\sigma_{\text {rms }}$ & \multicolumn{2}{l|}{ Discrepancy Ratio (\%) } \\
\cline { 4 - 5 } & $\mathrm{E}_{\text {mean }}(\%)$ & $\mathbf{1 / 2} \mathbf{- 2 . 0}$ & $\mathbf{1 / 4} \mathbf{- 4 . 0}$ \\
\hline SED1 $(\varepsilon=0.002)$ & 65.3 & 0.95 & 59.4 & 26.0 \\
\hline SED2 $\left(\varepsilon=\varepsilon_{\text {Ba07) }}\right.$ & 66.3 & 1.07 & 72.9 & 40.6 \\
\hline Watanabe $(1992)(A=2.0)$ & 64.6 & 0.27 & 26.0 & 2.1 \\
\hline Bodge $(1989)-\mathrm{k}=1 / 1.74$ & 106.4 & 1.04 & 60.4 & 32.3 \\
\hline Bagnold $(1963)-\mathrm{k}=1 / 5.81$ & 73.6 & 0.87 & 43.8 & 30.2 \\
\hline
\end{tabular}


For the laboratory experiments, as seen from Table 3, the SED1 has the least discrepancy ratio such that $91 \%$ (1-Disc.Ratio) of the predicted data lies within a factor of 0.25-4.0 of the measured values and it gives smaller mean absolute error together with the Bodge's (1989) expression. Watanabe (1992) approach shows similar scatter with the SED1, yet, the mean absolute percent error increases up to $56 \%$.

For the field experiments, as seen from Table 4, the SED1 approach has a similar mean absolute error with the SED2 and Watanabe approaches ( 65\%) and 74\% (1-Disc.Ratio) of the predicted data lies within a factor of $0.25-4.0$ of the measured values. As it is seen from the mean absolute errors and the discrepancy ratios, there exists a high uncertainty in predicting the sediment transport rates, which is a commonly known fact for almost any type of sediment transport formulas as these approaches mostly depend on some calibration with the available data sets.

\section{CONCLUSION}

From the comparative studies, it has been observed that $91 \%$ and $74 \%$ of the predicted transport rates using the SED1 approach lies within a factor of 0.25-4.0 of the measured values for the selected laboratory and field experiments, respectively, using a constant coefficient $(\varepsilon=0.002)$ for both, where such empirical coefficients might show variability for laboratory and field conditions as given in Table 3 and Table 4 for the Watanabe (1992), Bagnold (1963) and Bodge (1989) expressions. The advantage of using a single empirical constant for both laboratory and field experiments might be attributed to the use of fall velocity in the expression.

In conclusion, an alternate approach (SED1) has been proposed based on the assumption that the distributed total LST rates across the surf zone are proportional to the product of rate of dissipation of wave energies due to wave breaking and wave-induced depth-averaged current velocities. The proposed approach is essentially based on the derivation of Bayram et al.'s (2007) total load formula in cross-shore direction. The validation of the proposed approach has been done by the available data sets of laboratory and field experiments. The proposed approach is found to be in good agreement with the measurements both qualitatively and quantitatively, especially for the cases where the wave conditions are highly energetic (both for plunging and spilling type breakers) and the suspended load is the main mode of sediment transport in the surf zone. However, the median grain size diameters in the experiments $(0.15 \mathrm{~mm}$ for the laboratory and $0.17 \mathrm{~mm}$ for the field experiments $)$ are in the same order of magnitude and the wave conditions are highly energetic (plunging and spilling type breakers). Therefore, the proposed approach requires further validation studies with different datasets of various grain size diameters and wave conditions and recently developed more sophisticated transport formulas.

\section{ACKNOWLEDGMENTS}

The authors would like to acknowledge Prof. Dr. Yoshimi Goda, Prof. Leo van Rijn, Mark B. Gravens and Atilla Bayram for their assistance in compiling and interpreting the data sets of several field and laboratory experiments referred in this study. This study was partially supported by the Scientific and Technological Research Council of Turkey (TÜBİTAK) Research Grant No: 108M589, "Coastal Vulnerability Assessment to Climate Change Supported with A Numerical Sedimentation Model".

\section{REFERENCES}

Ackers, P. and White, W.R. 1973. Sediment transport: new approach and analysis. Journals of Hydraulics Division 99 (1), .2041-2060.

Ahrens, J.P. 2000. The fall-velocity equation. Journal of Waterways, Port, Coastal, Ocean Eng., 1262, 99-102.

Bagnold, R.A. 1963. Beach and nearshore processes Part I: Mechanisms of marine sedimentation, in The Sea: Ideas and Observations, 3, M. N. Hill (ed.), Interscience, New York, 507-528.

Baldock, T.E., Holmes, P., Bunker, S., and Van Weert, P. 1998. Cross-shore Hydrodynamics within an Unsaturated Surf Zone, Coastal Eng., 34, 173-196.

Baykal, C. 2012. Two-Dimensional Depth-Averaged Beach Evolution Modelling, Ph.D. Thesis, Middle East Technical University, Ankara, Turkey 
Bayram, A., Larson, M., Miller, H.C., Kraus, N.C. 2001. Cross-shore distribution of longshore sediment transport: comparison between predictive formulas and field measurements. Coastal Eng. 44, 79-99.

Bayram, Larson and Hanson. 2007. A new formula for the total longshore sediment transport rate, Coastal Engineering, Elsevier, 54, 700-710.

Bijker, E.W. 1967. Some considerations about scales for coastal models with movable bed. Delft Hydraulics Laboratory, Publication 50, Delft, The Netherlands.

Bijker, E.W. 1971. Longshore transport computations. Journal of the Waterways, Harbors and Coastal Eng. Division 97 (4), 687-703.

Bodge, K.R. 1989. A literature review of the distribution of longshore sedimenttransport across the surf zone, Journal of Coastal Research, 5(2), 307-328.

Camenen, B. and Larson, M. 2005. A general formula for non-cohesive bed load sediment transport. Estuarine, Coastal and Shelf Science 63, 249-260.

Camenen, B. and Larson, M. 2007. A unified sediment transport formulation for coastal inlet application. Technical Report ERDC/CHL CR-07-1, US Army Engineer Research and Development Center, Vicksburg, MS.

Camenen, B. and Larson, M. 2008. A general formula for noncohesive suspended sediment transport. Journal of Coastal Research 24 (3), 615-627.

Engelund, F., Hansen, E. 1967. A Monograph on Sediment Transport in Alluvial Streams. Teknisk Forlag, Copenhagen, Denmark.

Gravens, M.B. and Wang, P. 2007. Data report: Laboratory testing of longshore sand transport by waves and currents; morphology change behind headland structures. Technical Report, ERDC/CHL TR-07-8, Coastal and Hydraulics Laboratory, US Army Engineer Research and Development Center, Vicksburg, MS.

Inman, D.L., and Bagnold, R.A. 1963. Beach and nearshore processes Part II: Littoral processes, in The Sea: Ideas and Observations, 3, M.N. Hill (ed.), Interscience, New York, 529-553.

Janssen, T.T. and Battjes, J.A. 2007. A note on wave energy dissipation over steep beaches. Coastal Eng., 54, 711-716

Kamphuis, J.W. 1991. Alongshore sediment transport rate. Journal of Waterway, Port, Coastal, and Ocean Engineering 117 (6), 624-641.

Kobayashi, N., Agarwal, A. and Johnson, B.D. 2007. Longshore current and sediment transport on beaches. Journal of Waterway, Port, Coastal, and Ocean Engineering, 133 (2007), 296-304.

Kuriyama, Y. 2010. Prediction of cross-shore distribution of longshore sediment transport rate in and outside the surf zone. Rep. Port and Airport Res. Inst., Vol.49, No.2.

Miller, H.C. 1999. Field measurements of longshore sediment transport during storms, Coastal Engineering, 36, 301-321.

USACE. 1984. Shore Protection Manual. Department of the Army, U.S. Corps of Engineers, Washington, DC 20314.

Van Maanen, B., de Ruiter, P.J. and Ruessink, B.G. 2009. An evaluation of two alongshore transport equations with filed measurements. Coastal Eng., Vol.56, 313-319.

Van Rijn, L.C. 1984. Sediment transport: Part I: Bed load transport; Part II: Suspended load transport; Part III: Bed forms and alluvial roughness. Journal of Hydraulic Division 110 (10), 1431-1456; 110 (11) 1613-1641; 110 (12) 1733-1754.

Wang, P., Smith, E.R. and Ebersole, B.A. 2002. Large-scale laboratory measurements of longshore sediment transport under spilling and plunging breakers. Journal of Coastal Research 18 (1), 118-135.

Watanabe, A., 1992. Total rate and distribution of longshore sand transport, Proc. of the 23rd International Coastal Engineering Conference, ASCE, 2528-2541. 